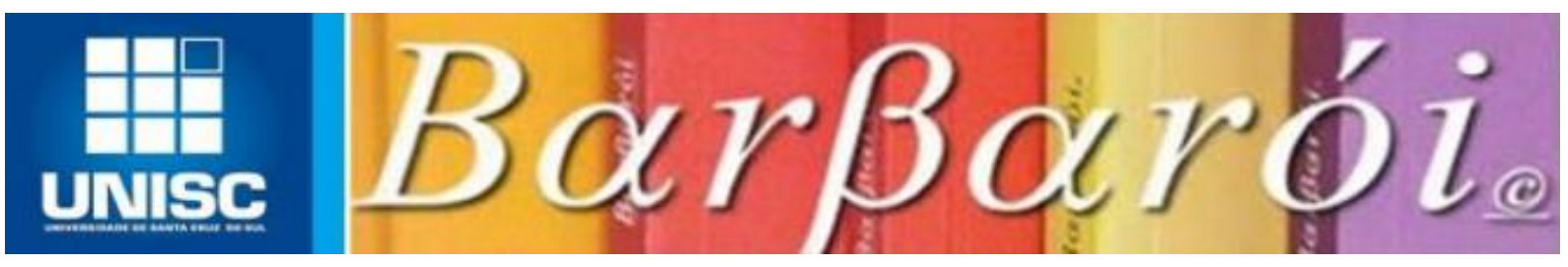

\title{
PERFORMANCES OU IDEOLOGIA DE GÊNERO? UMA APROXIMAÇÃO AO PENSAMENTO DE JUDITH BUTLER
}

\author{
DOI: http://dx.doi.org/10.17058/barbaroi.v51i1.12187 \\ Márcio Bruno Barra Valente \\ Universidade da Amazônia - UNAMA - Brasil \\ Bárbara Araújo Sordi \\ Universidade da Amazônia - UNAMA - Brasil \\ Maria Lúcia Chaves Lima \\ Universidade Federal do Pará - UFPA - Brasil
}

\section{RESUMO}

Há quase 30 anos, as contribuições teóricas e políticas da filósofa estadunidense Judith Butler têm recebido destaque no cenário mundial, ao buscar problematizar alguns conceitos, como o de gênero, e provocar desconstruções dentro da própria teoria feminista. Considerando a relevância da autora para a atualidade, objetiva-se neste artigo realizar uma aproximação à sua obra, apresentando noções como sujeito, corpo, materialidade, corpos abjetos e performance de gênero para problematizar sobre a suposta "ideologia de gênero", da qual ela seria uma das proponentes. Uma pergunta acompanha a presente análise: por que o pensamento de Butler é tão ameaçador? Criar a ideia de que os estudos sobre gênero constituem uma ameaça à família acaba por se tornar uma forma de mobilização social, por meio do medo e do ódio com fins políticos, por vezes, conservadores e, perigosamente, extremistas.

Palavras-chave: Gênero; teoria queer; performances de gênero.

\section{INTRODUÇÃO}

Judith Butler tem recebido destaque por suas contribuições teóricas nos estudos de gênero. Filósofa pós-estruturalista americana, tem sua ascendência na Hungria e Rússia, carregando em si a herança psíquica do holocausto e a marca de ser judia. Além disso, sua história também é assinalada por violências de gênero e sexualidade, fatores que terão repercussão ao longo de seu trajeto acadêmico e histórico (PORCHAT, 2014).

Suas contribuições têm sido ressaltadas, no cenário nacional e mundial, ao buscar problematizar conceitos e provocar desconstruções dentro da própria teoria feminista. Dentre suas inquietações e provocações, propõe questionar a própria categoria de gênero - tão cara ao feminismo, no sentido de diferenciar a cultura do biológico - pois, em seu entender, gênero, da maneira como vem sendo trabalhada, também estaria calcado no sexo biológico. 
Diante da relevância da obra de Butler, este artigo se configura como uma aproximação com os conceitos de sujeito, corpo, materialidade e performances de gênero, para então discutir acerca da suposta "ideologia de gênero", da qual a filósofa seria uma das proponentes, assunto bastante recorrente no Brasil, tendo interferido, inclusive, nos currículos escolares, em projeto de lei e no próprio ataque à teórica, em sua vinda ao Brasil.

Para tanto, apresenta-se brevemente a trajetória dos estudos feministas sobre a noção de gênero, o conceito de sujeito, corpo e materialidade, a noção de performance de gênero para Butler. Por fim, analisa-se sobre a instigante repercussão da vinda da filósofa ao Brasil, em novembro de 2017, no debate sobre gênero e sexualidade. Problematizar essa experiência é pertinente, com fim não apenas de evidenciar a materialidade da teoria da autora, mas pelo propósito político que seus pressupostos teóricos propõem e que este artigo também almeja alcançar.

\section{Estudos feministas de gênero}

Os estudos sobre gênero ressurgiram nos anos 60 do século XX, em função dos movimentos feministas que exigiam compreender e explicar a condição de subordinação das mulheres.

A primeira proposta do movimento feminista foi construir uma teoria revolucionária capaz de quebrar a dominação dos homens. Tal dominação não estava localizada em um espaço específico, nem centralizada na figura do Estado, mas estava diluída em diferentes espaços sociais: nas instituições públicas e privadas, igrejas, ruas, residências, universidades etc. Não obstante, identificou-se a subordinação feminina como produto da ordem patriarcal que atravessava todos os espaços sociais (BARBIERE, 1993).

Bento (2006) afirma que, inicialmente, os estudos sobre os gêneros, que explicavam a subordinação das mulheres, foram construídos com base na tradição do pensamento moderno, cuja interpretação sobre os gêneros se estruturava a partir de uma perspectiva oposicional/binária e de caráter universal. Para autora, o livro O segundo sexo, de Simone de Beauvoir, publicado originalmente em 1949, é um marco para o movimento feminista, uma vez que radicalizou a perspectiva de oposição entre homens e mulheres, por meio da compreensão dos processos históricos que legitimavam a subordinação feminina e por ter evidenciado mecanismos que dariam consistência ao "tornar-se" mulher, para além das características biológicas que legitimavam sua suposta inferioridade, constituindo-se, então, em um movimento teórico de desnaturalização. 
Contudo, Bento (2006) destaca que o corpo, nesse momento, é pensado de forma binária. Ou seja, para Beauvoir, os corpos estariam divididos entre os sexos masculino e feminino, com suas características biológicas peculiares e naturais, sendo que cada sociedade imprimiria nesses corpos suas marcas, valores, normas, sentidos, constituindo homens e mulheres que, radicalmente, se diferenciariam também enquanto gêneros e subjetividades.

Nesse período do feminismo, a visibilização da mulher, enquanto categoria universal e do status universal do patriarcado, correspondia a uma necessidade de fortalecer as reivindicações do feminismo, através de uma identidade coletiva que mais tarde se traduziria nas discussões políticas e sua visibilidade nos espaços públicos.

Entretanto, assinala Bento (2006), simultânea ao processo de institucionalização do feminismo, inicia-se uma discussão em seu interior acerca dessa estrutura conceitual marcada pela oposição universal do sexo. Para a autora, a mudança que ocorre é orientada, especialmente, pelas concepções de poder e da dimensão relacional para a construção das identidades de gênero.

Uma das mudanças empreitadas especialmente nos anos 1990 foi o surgimento de estudos sobre as relações homem-mulher, mulher-mulher e homem-homem, embora ainda houvesse um predomínio dos estudos sobre as mulheres. Outra mudança foi que os estudos de gênero passaram a ser efetuados também por pesquisadores homens, com foco sobre os homens e as masculinidades, e que o termo "gênero" deixou de ser sinônimo de mulher, feminismo ou estudo sobre mulheres (SCOTT, 1995).

Bento (2006) sustenta que os estudos sobre as relações de gênero foram consolidados a partir da desconstrução da mulher universal, apontando outras variáveis sociológicas (etnia, classe, religião, sociedade etc.), as quais foram articuladas, a fim de redefinir a identidade da mulher, que se fragmentou ou se diversificou em mulheres negras, brancas, pobres, camponeses, citadinas, lésbicas etc.

Esse momento significou uma ruptura do olhar que posicionava a mulher como portadora de uma condição universal subordinada, a qual, ao longo da história (e ainda hoje), reiterou representações como da mulher-vítima e do homem-inimigo. Ao mesmo tempo, tal ruptura possibilitou o olhar relacional, cuja premissa básica é de que o masculino e o feminino se constroem relacionalmente e de forma simultânea, e não em oposição radical.

Para Bento (2006), o nome de Joan Scott é fundamental, nessa época, uma vez que foi ela quem apontou a necessidade de se criar instrumentos analíticos capazes de permitir que os estudos se descolassem da empiria. Com a leitura de autores como Michel Foucault, com sua 
genealogia do poder, e Jacques Derrida, com seu projeto desconstrutivista, Scott (1995) definiu gênero como (1) um elemento constitutivo das relações sociais baseadas nas diferenças percebidas entre os sexos e (2) uma forma primária de dar significado às relações de poder, ou melhor, um campo no interior do qual, ou por meio do qual, o poder é articulado.

De acordo com Scott (1995), o termo "gênero" deve ser usado como categoria analítica, isto é, um instrumento metodológico para produção de conhecimentos em torno da construção, da reprodução e das mudanças de identidade de gênero. A autora, segundo Bento (2006, p. 75), "propõe um conceito que visa abordar gênero a partir de uma ótica mais sistêmica, ao mesmo tempo em que chama a atenção para a necessidade de os cientistas tornarem-se mais autoconscientes da distinção entre vocabulário analítico e o material estudado". Portanto, afirma a importância de um instrumental que possibilitasse perguntar sobre os processos históricos e políticos que articulassem a formar determinadas relações entre homens e mulheres, retirando, assim, a suposta atemporalidade da estrutura binária e hierárquica como fato natural.

No entanto, Bento (2006) argumenta que, nas duas perspectivas dos estudos de gênero apresentadas - a primeira identificada como "universal" e a segunda, "relacional" -, a sexualidade, o gênero e a subjetividade foram pensados dentro de uma relação binária, por mais que tivessem a proposta de rompê-la. A autora enfatiza que foram os estudos queer que apontaram o heterossexismo das teorias feministas e possibilitaram, ao mesmo tempo, uma despatologização das experiências identitárias e sexuais interpretadas como "problemas individuais" - transexuais, por exemplo, como se propôs a autora - e uma especial atenção às performances que provocam fissuras nas normas de gênero.

A autora ressalta que os limites dos estudos de gênero foram evidenciados por autores e autoras - Michel Foucault, Gilles Deleuze, Jeffrey Weeks, Gayle Rubin, Butler, Eve Sedgwick, para citar apenas alguns nomes - que argumentavam em favor de um deslocamento teórico entre estudos sobre gênero e sexualidade, a fim de favorecer a visibilidade de grupos que divergiam das normas heterossexuais, por exemplo, o lésbico, a princípio, e o transexual, posteriormente. O desafio era construir teorias que habilitassem tais grupos, mas, ao mesmo tempo, que se contrapusessem a uma explicação referenciada nos corposexuados e produzissem contradiscursos ao saber científico hegemônico.

A história da sexualidade I: A vontade de saber, de Foucault, evidencia os limites dos estudos de gênero, iniciando uma maneira de problematizar a sexualidade. Em linhas gerais, o autor sublinha que nossas ideias sobre sexualidade são construções modernas, pois datam do 
final do século XIX, cujo marco se processou a partir da invenção do "homossexual" e, ao mesmo tempo, da sexualidade "verdadeira", isto é, a heterossexual. Assim, aquilo que se julgava tão individual, a sexualidade, "seria resultado de uma articulação histórica do dispositivo poder-saber, que põe e expõe o sexo em discursos, produzindo efeitos sobre os corpos e as subjetividades" (BENTO, 2006, p. 78). E, sendo a sexualidade construída com base em determinados dispositivos, como ficariam as teorias e movimentos políticos que se aglutinassem em torno de uma identidade sexual?

Na visão de Bento (2006), o terceiro momento dos estudos de gênero diz respeito à problematização da vinculação entre gênero, sexualidade e subjetividade, perpassada por uma leitura do corpo como significante em permanente processo de construção e múltiplos significados.

Butler (2008) problematiza as teorias feministas, denunciando que estas vinculam o gênero à estrutura binária, na qual há a pressuposição da heterossexualidade. Dessa maneira, torna-se referência nos estudos queer, ao asseverar que os sexos não têm nenhuma validade ontológica e o gênero não é uma parte natural de uma pessoa, mas algo ao qual elas devem estar constantemente sendo expostas e solicitadas a representar - o que será chamado de "performances de gênero".

Para a autora, o termo "gênero", utilizado pelas feministas, apoiado na teorização da construção social, acabara por assemelhar-se ao termo "sexo", quando a cultura parece ser essencial para determinar o sexo, uma categoria pré-discursiva, vazia. Sexo e gênero seriam ambos elementos discursivos e, se existem gêneros que escapam à lógica da inteligibilidade, não é por uma escolha. Nesse sentido, propõe uma teoria performática, em que gênero seria um efeito discursivo, enquanto sexo (e sua leitura), um efeito de gênero (BUTLER, 2003; PEDRO, 2005; PORCHAT, 2014), aspecto que abordaremos de forma mais detalhada a seguir.

\section{Sujeito, corpo e materialidade}

Tomar a construção do sujeito como uma problemática política não é a mesma coisa que acabar com o sujeito; desconstruir o sujeito não é negar ou jogar fora o conceito; ao contrário, a desconstrução implica somente que suspendemos todos os compromissos com aquilo a que o termo "o sujeito" se refere, e que examinamos as funções lingüísticas a que ele serve na consolidação e ocultamento da autoridade. Desconstruir não é negar ou descartar, mas pôr em questão e, o que talvez seja mais 
importante, abrir um termo, como sujeito a uma reutilização e uma redistribuição que anteriormente [as mulheres] não estavam autorizadas (BUTLER, 1998, p. 24).

Em Fundamentos contingentes: feminismo e a questão do "pós-modernismo”, Butler (1998) questiona se a forma de as mulheres se constituírem como sujeito, a partir do modelo que produzem em seus estudos e práticas feministas, não acabaria por lançar novamente uma região de degradação, tal como as que tentavam desconstruir, pois estariam construindo novamente um lugar de exclusão, oposição e, ainda, uma produção de abjetos sociais, dos anormais, isto é, aqueles que escapam e subvertem a lógica heteronormativa, a qual pressupõe uma coerência entre sexo, gênero, desejo e prática sexual, que tornam os gêneros inteligíveis. E indaga se não seria importante que os estudos feministas se propusessem um processo autocrítico acerca dos processos que produzem e desestabilizam as categorias de identidade.

Com sua questão, a autora convoca o movimento feminista a refletir sobre a necessidade de se falar enquanto mulher e pelas mulheres, de evocar uma representação, uma especificidade que agregaria todas as mulheres. A autora reconhece que, quando se invoca a categoria mulheres, como se estivesse descrevendo a clientela a que o feminismo alude, inicia-se um debate interno sobre o conteúdo descritivo do termo, pois há quem diga que a ontologia feminina resida na maternidade, seja biológica, seja social, assim como há quem destaque as manifestações das mulheres na comunidade ou seus modos de conhecerem. Mas, quando se articula uma identidade, há resistência, formação de facções dentro do movimento "unificado" ou sua completa rejeição.

Butler (1998) argumenta que, embora reconheça a dificuldade de construir uma política nos Estados Unidos (no Brasil, talvez não seja diferente), cuja tradição é da representação, sem recorrer ao lobby da identidade, é preciso a autocrítica, pois "é certo que nem todas as mulheres são mães: algumas não podem sê-lo, algumas são jovens ou velhas demais para sê-lo, outras escolhem não sê-lo, e para algumas que são mães, esse não é necessariamente o ponto central de sua politização no feminismo" (BUTLER, 1998, p. 24).

A autora afirma que é fundamental pensar as categorias de identidade, não como meramente descritivas, mas sempre normativas e, por isso, exclusivistas. Todavia, não refuta o uso do termo "mulheres", porém, destaca a importância de pressupor que essa expressão designa um campo de diferenças indesignável, o qual não pode ser totalizado ou resumido por uma identidade descritiva. De fato, o termo precisa se tornar um lugar de permanente abertura e ressignificação. 
Assim, o sujeito do feminismo não deve ser morto ou descartado, mas, ao contrário, é preciso "liberar o termo num futuro de múltiplas significações, emancipá-lo das ontologias maternais ou racistas às quais esteve restrito e fazer dele um lugar onde significados não antecipados podem emergir" (BUTLER, 1998, p. 25). O sujeito, para a autora, seria este alguém que não se definiria por ontologias, naturais ou culturais. Logo, ele não estaria restrito à suposta diferença anatômico-fisiológica, anterior à linguagem, pré-discursiva, nem mesmo a uma folha branca ou corpo nu aguardando as marcas da cultura, do gênero. Tais elementos "naturais" ou "culturais", que descrevem os corpos e marcam identidades, lugares, papéis, trânsitos, relações sociais etc., não seriam despretensiosos, mas prescrições das normas.

Não há um sujeito feminino - masculino, transexual, pai etc. - por trás das especificidades, expressões e marcas que decorrem dessa identidade de gênero. Para a autora, conceber isso seria reiterar a ontologia em torno dos gêneros, do sexo. As "especificidades", "expressões" e "marcas" supostas enquanto resultados são elas próprias elementos que constituem o sujeito feminino, são performances que estabilizam o sujeito em uma coerência dos gêneros, na inteligibilidade social de gêneros, um conjunto de atos repetidos no interior de uma estrutura cristalizada e binária, são efeitos de práticas reguladoras que visam a produzir uma substância, um ser "mulher", um sujeito feminino.

Para Butler (2001), o que está em jogo na reformulação da materialidade dos corpos é que, primeiramente, a matéria dos corpos é indissociável das normas regulatórias que governam sua materialização e a significação dos efeitos materiais. Nesse sentido, a construção do sexo não é um dado natural sobre o qual o construto do gênero é artificialmente imposto, contudo, é uma norma cultural que governa a materialização dos corpos. A norma corporal não é assumida, apropriada, adotada pelo sujeito, pois o "eu" falante é formado em virtude de ter passado pelo processo de assumir um sexo. Por fim, o sujeito é constituído através da força da exclusão e da abjeção, ou seja, os meios discursivos pelos quais o imperativo heterossexual se reitera e possibilita certas identificações sexuadas e impede ou nega outras, as identidades abjetas.

Butler (1998) submete, portanto, a noção de corpo e de materialidade à mesma crítica desconstrutiva à qual submeteu o sujeito feminino. Mas, como conceber a desconstrução de algo tão real e palpável? O corpo e sua materialidade, suas características anatômicofisiológicas, a diferença dos sexos, o pênis e a vagina? A autora, a princípio, afirma que "problematizar a matéria dos corpos acarreta, em primeiro lugar, uma perda da certeza epistemológica" (BUTLER, 1998, p. 26). O corpo é postulado ou significado como prévio, 
anterior à significação, pré-linguístico. Porém, essa significação funcionaria mediante a produção de um efeito de seu próprio procedimento, ou seja, se o corpo significado como prévio à significação é um efeito da significação, o estatuto mimético ou representativo da linguagem para a qual o signo segue os corpos como seus espelhos necessários seria um equívoco, pois de forma alguma há mimetismo. $\mathrm{O}$ ato de significação é constitutivo, performático, produtivo do corpo, o qual, então, se encontra como anterior a significação.

Ao tratar de corpo, a autora enfatiza que a diferença sexual (o pênis e a vagina, o escroto e o útero, como alguns exemplos) não é simplesmente uma função de diferenças materiais, mas que são marcadas e formadas por práticas discursivas. Por isso, a categoria "sexo" é, desde o início, normativa:

O "sexo" não apenas funcionaria como uma norma, mas é parte de uma prática regulatória que produz corpos que governa, isto é, toda força regulatória manifestase como uma espécie de poder produtivo, o poder de produzir - demarcar, fazer circular, diferenciar - os corpos que controla. Assim, o "sexo" é um ideal regulatório cuja materialidade é imposta: esta materialização ocorre (ou deixa de ocorrer) através de certas práticas altamente reguladas. [...] o "sexo" é um construto ideal que é forçosamente materializado através do tempo. Ele não é simples fato ou condição estática de um corpo, mas um processo pelo qual as normas regulatórias materializam o "sexo" e produzem essa materialização através de uma reiteração forçada destas normas (BUTLER, 2001, p. 153-154).

Butler (2001) é precisa nessa citação, ao evidenciar como a categoria "sexo" produz e regula a inteligibilidade da materialidade dos corpos. Nesses dois momentos, a categoria impõe uma dualidade e uma uniformidade sobre os corpos, a fim de manter a sexualidade reprodutiva como uma ordem compulsória. Isso se daria, não de maneira estável, mas processualmente, ou seja, a materialidade do corpo é processual. É reiterada diariamente, como, por exemplo, nas portas dos banheiros com seus símbolos que "representam" o masculino e o feminino.

No entanto, o fato de a reiteração ser necessária torna evidente que seu caráter nunca é totalmente completo, ou seja, os corpos não se conformam completamente às normas pelas quais suas materializações são impostas. Nesse sentido, Butler (2001) argumenta que são justamente as instabilidades, as brechas e as fissuras, as possibilidades de rematerialização, abertas por esse mesmo processo, que marcam um domínio no qual a força da lei regulatória 
pode se voltar contra ela mesma, para gerar rearticulações que colocam em questão a própria força hegemônica daquela mesma lei regulatória.

Diante dessa conclusão, a autora se questiona: como a noção de performatividade de gênero se relaciona com tal concepção de materialização?

\section{As performances de gênero}

O fato de a realidade de gênero ser criada mediante performances sociais contínuas significa que as próprias noções de sexo essencial e de masculinidade ou feminilidade verdadeiras ou permanentes também são construídas, como parte da estratégia que oculta o caráter performático do gênero e as possibilidades performativas de proliferação das configurações de gênero fora das estruturas restritivas da dominação masculinista e da heterossexulidade compulsória (BUTLER, 2008, p. 201).

Bento (2006) afirma que pensar as relações entre gênero e corpo parece ser uma das preocupações centrais da obra de Butler e de outras feministas queer. O pensar é aqui usado no sentido de problematizar os processos que se articulam para dar a tal relação uma aparência a-histórica e destituída de conteúdo político.

O gênero precisa ser analisado como uma sofisticada tecnologia social heteronormativa que é operacionalizada pelas instituições médicas, linguísticas, domésticas, escolares, as quais produzem constantemente corpos-homens e corpos-mulheres. A heterossexualidade, assim, constitui-se como uma matriz que cultiva, confere sentido e legitimidade às diferenças sexuais "existentes" nos corpos, enquanto aparências "naturais" e dispositivos naturais da heterossexualidade dos mesmos.

Butler (2008) argumenta que é a partir de reiterações contínuas em torno das supostas “diferenças" sexuais existentes nos corpos, as quais se realizam mediante interpretações em ato das normas de gênero, que os corpos adquirem sua aparência de gênero, assumindo-se como corpo-homem ou corpo-mulher, em uma série de atos que são renovados, revisados e consolidados no tempo. A autora chama esse processo de performatividade de gênero.

Talvez seja justamente tal noção de performances de gênero que materialize o radicalismo do pensamento de Butler. Ao desnaturalizar e dessencializar os gêneros, os sexos e as sexualidades outrora fixadas na materialidade do corpo, a autora argumenta que tais elementos não são intrínsecos, mas se constituem nas performances de gênero (naquilo que a estrutura heterossexual normatiza como masculino e feminino) que produzem a suposta 
materialidade do corpo e sua pretensa coerência e estabilidade de gêneros, sexos e sexualidade.

A performatividade não é um "ato" singular ou deliberado, entretanto, ao contrário, uma prática reiterativa e citacional pela qual o discurso produz os efeitos que ele nomeia. As normas regulatórias de "sexo" trabalham de uma forma performática, a fim de construir a materialidade dos corpos, ou melhor, para materializar o sexo do corpo, a diferença sexual a serviço da consolidação do imperativo heteronormativo.

De acordo com Butler (2001), o que constitui a fixidez do corpo, seus contornos, sensações, delineamentos e movimentos é plenamente material, mas tal materialidade precisa ser repensada como efeito do poder, como efeito mais produtivo do poder. Ou seja, o "sexo" precisa ser compreendido em sua normatividade e não separado da materialidade do corpo, isto é, da materialização da norma regulatória.

Bento (2006), a partir de Butler, argumenta que, antes de nascer, o corpo já está inscrito em um campo discursivo determinado com expectativas estruturadas em uma complexa rede de pressuposições sobre seu comportamento, gostos e subjetividades que acabam por antecipar o efeito que se supunha causa. Por exemplo, quando um médico, após uma ultrasonografia, afirma "é um menino ou é uma menina”, não está descrevendo um dado constatado, mas produzindo uma invocação performática que amarra as possibilidades e os limites performáticos de gênero, nesse ato fundacional. Ou seja, a partir do "é um menino", instala-se um conjunto de expectativas e suposições em torno do corpo, sendo em torno delas que se estruturam as performances de gênero, prescrevendo o que seria mais natural, o mais apropriado para ele:

O "sexo" é, pois, não simplesmente aquilo que alguém tem ou uma descrição estática daquilo que alguém é: ele é uma das normas pelas quais o "alguém" simplesmente se torna viável, é aquilo que qualifica um corpo para a vida no interior do domínio da inteligibilidade cultural (BUTLER, 2001, p. 155).

“Alguém" se torna viável pelo sexo; é ele que qualifica um corpo para vida inteligível, para vida humana. De fato, ele é humano, por ter um sexo estável, coerente com as performances de gênero que se espera ou se supõe a ele amarrados. "Há uma amarração, uma costura, ditada pelas normas, no sentido de que o corpo reflete o sexo, e o gênero só pode ser entendido, só adquire vida, quando referido a essa relação” (BENTO, 2006, p. 89). 
Uma experiência parece ilustrar o quanto as performances de gênero que se articulam fora dessa amarração são postas à margem, marginalizadas, encaradas como abjetas, ao não romperem a suposta coerência e estabilidade. Certo dia, o primeiro autor deste artigo estava no cinema assistindo o filme A Era do Gelo $3^{1}$. Nesse filme, há um personagem chamado Sid, a preguiça, que se desentende quando seu amigo Manny constitui sua própria família. Após o desentendimento, Sid parte à procura de novos amigos, de uma nova família. Em sua jornada, encontra três ovos e assume-os como sendo seus "filhos", embora Manny afirme que ele é um péssimo pai, já que pegou ovos que pertenciam a alguém. Não obstante, Sid permanece com os ovos, especialmente depois que percebe que dentro deles há vida (pela incidência de luz sobre os ovos, que permite que veja silhuetas). Quando os ovos se quebram, para a sua e nossa surpresa, nascem três dinossauros que, imediatamente, avançam sobre Sid, chamando-o repetidas vezes de "mamãe". Por sua vez, quando o vemos ser afagado por "seus" filhos, Sid, com um sorriso na cara, diz: "eu sou mamãe".

Não serão destacadas outras cenas do filme, afinal, este artigo não tem como objetivo fazer interpretação ou análises das performances de gênero nele presentes, mas frisar o que ocorreu na própria sala de cinema. Após a cena descrita, uma criança falou para uma senhora, “mãe, ele não pode ser mamãe... ele é homem, é papai”. A dúvida da criança é respondida sucintamente: "é porque ele é doido".

Como ensina Butler (1998; 2008; 2001), é o sexo que torna “alguém" viável, inteligível para a vida humana. Ou melhor, quando o corpo reflete o sexo e o gênero sutura a relação entre ambos, sugerindo uma estabilidade e coerência, alguém se torna viável, pertencente à inteligibilidade de gênero, a matriz heterossexual. Sid, a preguiça, é apresentado no filme como um corpo-homem, todavia, ao se reconhecer como "mamãe", acaba por gerar uma fissura na estabilidade e coerência supostas, pois, sendo um corpo-homem, deveria ser um papai e não uma mamãe. O diagnóstico da mãe acerca do comportamento de Sid é coerente com a noção de abjeto, pois o louco, o doido, o doente mental é o oposto da coerência e estabilidade. Não apenas o filme, mas também a resposta da senhora à criança faz pensar na necessidade de reiteração da matriz heterossexual compulsória: é preciso reiterar, principalmente às crianças, a inteligibilidade identitária e afastar qualquer possibilidade de desvio.

Butler (2001) nomeia de abjetos aqueles que se desviam da lógica heteronormativa. Com o termo, pretende designar precisamente as zonas "inóspitas" e "inabitáveis" da vida

${ }^{1}$ A Era do Gelo 3 (Ice Age: Dawn of the dinosaurs). 96 min. EUA (2009).

Barbarói, Santa Cruz do Sul, n. 51, p.<1-20>, jan/jun, 2018 
social, as quais são densamente povoadas por aqueles que não gozam do status de sujeito, pois não se enquadram, ao fazerem tremer a estabilidade e a coerência entre corpos sexuados e a ordem dos gêneros; de fato, subvertem-na com performances que não refletem seus corpos-homens ou corpos-mulheres. Entretanto, os abjetos são necessários, para que o domínio do sujeito seja circunscrito: "a formação do sujeito exige uma identificação com o fantasma normativo do sexo: essa identificação ocorre através de um repúdio que produz um domínio de abjeção, um repúdio sem o qual o sujeito não pode emergir” (BUTLER, 2001, p. 156).

São as performances de gênero que suturam, amarram a relação entre corpo e sexo, produzindo o efeito de estabilidade e coerência que se julga serem suas causas. Elas não se processam a partir de um marco singular que ocorre no tempo, são sempre um processo temporal que atua através da reiteração de uma norma ou conjunto de normas, de modo que, desde o momento em que adquire o status de ato no presente, "ato" singular e apropriação por parte do sujeito, oculta ou dissimula sua historicidade, as convenções das quais ela é uma repetição. As performances possuem uma teatralidade, não no sentido de serem falsas, porém, justamente porque ganham certa inevitabilidade que decorre da impossibilidade de uma plena revelação de sua história, dos critérios de sua inteligibilidade que produziram e submetem os corpos.

\section{Impactos e distorções de Butler no Brasil atual}

Durante a elaboração deste artigo, aconteceu a visita de Judith Butler ao Brasil, em novembro de 2017, para ministrar uma palestra sobre "O fim da democracia", haja vista que seu último trabalho, "Caminhos divergentes: judaicidade e crítica do sionismo", pauta sobre sionismo e identidade dos povos israelense e palestinos. É digno de nota que os últimos estudos de Butler têm-se debruçado sobre autoritarismo, fragilidade dos sistemas democráticos e violências.

Contudo, um fervoroso boato espalhou-se em torno de sua apresentação, difundindo-se que a autora iria falar sobre "Ideologia de gênero", referindo-se ao livro Problemas de gênero: Feminismos e Subversão das identidades", publicado em 1989. Claramente desconhecendo os debates teóricos de ambos os livros citados, um grupo de pessoas acusou Butler de propagar "ideologia de gênero", pedofilia, zoofilia e corrupção de menores - fato que teve repercussão e foi noticiado inclusive internacionalmente. 
Butler foi chamada de "bruxa", comparada ao diabo e teve sua foto queimada em fogueira, em uma manifestação. Sendo alvo de agressões verbais, protestos e perseguições, durante sua estadia, percebe-se o quanto é espinhoso desconstruir naturalizações tidas como "verdades", de sorte que coube momentaneamente a imagem da professora como a personificação do "inimigo", os estudos de gênero. Esse acontecimento suscitou algumas questões: quem tem medo de falar sobre gênero? Por que falar sobre gênero causa tanta indignação? O que tornaria os estudos de uma pensadora uma ameaça concreta? Por que pensar sobre corpo, sexualidade e gênero pode ser tido como uma heresia ou com rompimento dos valores morais e da família?

Para adentrar nesse debate, com muito mais questionamentos do que respostas, é imprescindível circunscrever brevemente o cenário político brasileiro atual.

A Constituição do Brasil, promulgada em 1988 e chamada de "Constituição Cidadã", tem suas diretrizes fundamentadas nos tratados e documentos internacionais, os quais preconizam e defendem os Direitos Humanos. Nesse documento, já se encontra, no primeiro artigo, o fundamento da República Federativa: “a dignidade da pessoa humana". Há o destaque para o Art. 5, que legisla sobre os Direitos Fundamentais, assegurando a igualdade de todos perante a lei, sem distinção de qualquer natureza, e que, além de ser livre a manifestação de pensamento, ninguém poderá ser submetido à tortura, nem a tratamento desumano ou degradante.

Infelizmente, o cenário brasileiro aponta uma realidade controversa aos postulados legais preconizados pela Constituição: segundo mapa da violência do Brasil, de 2016, há a diminuição de assassinatos de pessoas brancas, enquanto há o aumento de assassinatos de pessoas negras; o fato se amplia, se adicionarmos o recorte de gênero, uma vez que as mulheres são as mais vulneráveis; a taxa de feminicídio no Brasil é a quinta maior do mundo; além disso, há um aumento no número de estupros: em 2016, houve um estupro coletivo a cada duas horas, enquanto o número de estupro aumentou 124\% em 5 anos (GELEDES, 2016; WAISELFISZ, 2016; ONU, 2016).

Segundo o Grupo Gay da Bahia (GGB), um homossexual morre a cada 25 horas, no país, sendo do Norte a liderança nesses assassinatos. Tais dados só evidenciam a necessidade do debate e de ações que pensem em políticas públicas que envolvam raça, classe, gênero e sexualidade.

É nesse sentido que os debates internacionais primam pela efetuação e garantia dos Direitos Humanos e têm se debruçado sobre violências e opressões em torno de sexo, 
sexualidade e gênero. Órgãos como a Organização das Nações Unidas (ONU) e a Organização dos Estados Americanos (OEA) destacam a importância do combate à violência e discriminação, quanto à orientação sexual e identidade de gênero, inclusive em práticas educativas (ONU, 2008; OEA, 2008).

No Brasil, pode-se observar que tais preconizações são pautas que envolvem o Plano da Educação. As Diretrizes Nacionais para a Educação em Direitos Humanos, homologada em 2012, afirma que, independentemente de sexo, orientação sexual e identidade de gênero, todas as pessoas devem usufruir de uma educação não discriminatória e democrática. Considerando obrigatória uma Educação pautada nos Direitos Humanos, o projeto políticopedagógico do Ensino Médio precisaria conter temas relativos a gênero, identidade de gênero, raça, orientação sexual, pessoas com deficiência, entre outros. Essas diretrizes também coadunariam com o Estatuto da Juventude, o qual afirma o dever de garantia do poder público ao Direito à Diversidade e à Igualdade.

O Plano Nacional de Educação, que determina diretrizes, metas e estratégias para a política educacional, a cada dez anos, não foi bem recebido por uma parcela da população, em 2014. Liderado por políticos fundamentalistas religiosos, surgiu um movimento contra a inclusão do que eles nomearam "ideologia de gênero".

Os conceitos de "ideologia" são polissêmicos. Abbagnano (2003) considera que ideologia é uma doutrina destituída da verdade objetiva, pois é mantida por interesses específicos, evidentes ou ocultos, daqueles que a utilizam. Já Marilene Chauí (2008), a partir de uma perspectiva marxista, irá desconstruir a ideia popular em torno do signo "ideologia". Para ela, tal termo comumente é utilizado como um ideário, ou seja, um acúmulo de ideias compartilhado socialmente, porém, a ideologia não seria um ideário qualquer, mas um produto político e social, circunscrito historicamente, tendo como fim manter desigualdade, exploração, ocultando um debate crítico acerca de uma realidade assimétrica, portanto, fruto de uma alienação. No entanto, ideologia não representaria o poder absoluto, podendo ser quebrada diante de uma organização social. Essas duas concepções do termo "ideologia" já circunscrevem várias confusões que a polêmica a respeito da hipotética "ideologia de gênero" tem protagonizado nos últimos anos, no Brasil.

O termo "ideologia de gênero" foi criado por Joseph Ratzinger, em 1997, que, ao tornar-se Papa Bento XVI, passou a atuar contra o feminismo e a suposta ideologia de gênero, considerando ataques à vontade de Deus, pois tais propostas tenderiam a anular a diferença 
natural. Desse modo, insiste na importância da diferença sexual e afirma que homem e mulher estão convocados a viverem próximos, completando-se nas suas diferenças:

Esta antropologia que pretendia dar igualdade à mulher, liberando-a de todo determinismo biológico, inspirou ideologias que põem em interdição a família natural composta por um pai e uma mãe, comparam a homossexualidade à heterossexualidade e defendem um novo modelo de sexualidade polimorfa. (RATZINGER, 2015 apud LIMA, 2015).

Posteriormente, o argentino Jorge Scala publica o livro La ideologia de genéro. $\mathrm{O}$ autor assevera que tal ideologia, ao negar a importância da biologia, permitiria que os sujeitos vivessem da forma que quisessem. Isso ocasionaria, então, a quebra da família tradicional, o direito ao aborto, entre outros aspectos considerados por ele como negativos (SCALA, 2011).

A partir dessa perspectiva, ideologia é vista como um instrumento de convencimento, persuasão, objetivando dominar o outro através da alienação. Ideologia de gênero seria uma doutrinação de falsas verdades, capaz de converter as pessoas à homossexualidade.

No entanto, discutir (e não propagar ideologia) sobre gênero na escola não significa em absoluto doutrinação, todavia, um modo de combater toda forma de discriminação e romper com rótulos estigmatizantes, os quais contribuem para uma sociedade assimétrica e segregadora. O desenvolvimento ético deve ser auxiliado pela educação, pelo acesso à informação e o esclarecimento, a fim de que o ser humano possa, não apenas a fazer escolhas eticamente acertadas, baseadas em situações práticas, mas assumir a responsabilidade por fazê-las (PASSOS, 2007).

A questão em torno da "ideologia de gênero" tem repercutido sobre os atuais Planos de Educação, desdobrando-se também em debates calorosos nas redes sociais e na comunidade, de maneira geral. Diante de um cenário político fragilizado, assistem-se a três grupos que aparentam ter propostas antagônicas: o primeiro, o qual defende a ideia da educação para todas e todos, como uma diretriz dos direitos humanos, reconhecendo os impactos que assolam homens e mulheres de diferentes identidades e orientação sexual, sustentando que, por meio da politização e pensamento crítico, se poderia melhorar índices estatísticos de violência e sofrimento psíquico; o segundo, o qual rejeita os estudos de gênero, acusando-os de não serem confiáveis, porque não são baseados em descobertas científicas, assim como recusa a ideia de ações e problematizações da temática "gênero" com crianças e adolescentes, argumentando que a imaturidade física e emocional seria terreno fértil para o incentivo da homossexualidade e um ataque ao modelo tradicional de família. Existe ainda 
um terceiro grupo, o qual não apenas rejeita os estudos de gênero, mas ataca qualquer referência a eles e às pessoas que os desenvolvem. Esse grupo pode ser confundido com o segundo, por vezes, mas ele não exige melhores argumentos científicos, tendo em vista o extremismo. Ele se baseia na proliferação do discurso do medo e do ódio.

De acordo com Reis e Egget (2017, p. 20), com apoio em discurso fundamentalista religioso, a falsa disseminação da "ideologia de gênero" como uma doutrina que seria imposta nas escolas contra valores morais e da família tem causado "pânico, retrocesso e demonização do inimigo". No entanto, a discussão de gênero, nas escolas (e não a suposta ideologia de gênero), tem como objetivo promover uma superação de desigualdades, fruto de debates democráticos que se consolidaram ao longo de ações, acordos e políticas públicas.

Em suma, associada à libertinagem, à indução à homossexualidade e a uma confusão dos papéis sociais, muitos brasileiros acreditam estar em frente de uma grande ameaça, que destrói princípios religiosos e científicos. Afinal, esses ensinamentos "subversivos" também teriam consequências sociais: mulheres ocupando lugares de homens, homens afeminados, casais não-reprodutivos e um sexo profano, fora da lógica binária pênis-vagina, desafiando a natureza e a biologia dos corpos ditos normais.

Porém, o próprio argumento dos que são contra a "ideologia de gênero" parece ser conflituoso em si: se a heterossexualidade é dada, é a norma, meninos são naturalmente fortes, viris, ao passo que meninas são em sua essência dóceis, cuidadoras, por que tanto medo em discutir gênero?

Judith Butler afirma justamente que a performatividade, pelas suas reiteradas repetições, é constituída de gestos estilizados, vindo de diversos polos discursivos (escolas, leis jurídicas, mídia, família, religião etc.) e que nem todas as pessoas conseguem se enquadrar, inclusive, homens e mulheres heterossexuais, os quais podem ter como consequências várias formas de sofrimento psíquico. Por não existir um modelo ideal e por advir de discursos, a performatividade permite que sujeitos sejam atores sociais de sua história e que possam "furar" a normatividade, escolhendo a forma mais viável de viver para si. A repetição abre brecha para fazer diferente, inclusive, pode ser denunciada a partir das paródias, o que demonstra a inexistência de uma naturalidade biológica determinista. Haveria, então, um reconhecimento, mesmo que velado, de que a coerência entre corpo, identidade, expressão e desejo é uma coerência fabricada por uma matriz heteronormativa compulsória?

Apesar de toda a repercussão envolvida com a vinda de Butler ao Brasil, a filósofa não fala de "ideologia de gênero"; ela discorre sobre a existência de uma matriz heterossexual, a 
partir da qual os discursos sobre sexo/gênero se inscreveriam antes mesmo de o bebê nascer, seja pela escolha do nome, seja pelas projeções dos pais, as roupas, a decoração do quarto etc. Estando circunscritos ao contexto social e histórico, esses discursos exigiriam uma performatividade que garantiria, por sua vez, além da inteligibilidade, um lugar na sociedade e na cultura, dentro das relações de poder.

Durante a já citada estadia de Judith Butler no Brasil, houve um protesto na frente do espaço de sua conferência, na qual as pessoas queimaram um boneco com o rosto da filósofa, acontecimento que nos remete à Santa Inquisição, quando mulheres que fugiam dos padrões e tinham outros conhecimentos, além do religioso, eram queimadas como pecadoras. Feministas, gays, lésbicas, pessoas trans e intersexos parecem ser as novas ameaças sociais: eles querem ocupar novos espaços de poder, modificar iniquidades, denunciar privilégios, e não aceitam docilmente o adestramento de seus corpos. Rompendo com a lógica de que o sexo biológico determina tudo que se é, parecem provocar um pensamento crítico e a necessidade da criação de novas políticas públicas democráticas. Mas seria interessante que mulheres, negros e negras, lésbicas, gays e trans tivessem as mesmas oportunidades que os homens heterossexuais brancos, os que ocupam os lugares mais privilegiados na sociedade? Por que o pensamento de Butler é tão instigante e ameaçador?

O cenário de retrocesso das conquistas dos direitos humanos, no país, é evidente. Principalmente desde o golpe parlamentar que tirou Dilma Roussef do posto de presidenta do Brasil, estamos assistimos ao desmonte de várias políticas sociais, como a votação de projetos de leis que aumentam e mantêm a vulnerabilidade das minorias políticas. A repercussão da vinda de Butler pode ser entendida dentro desse contexto mais amplo. Ela passou a ser identificada como uma poderosa proponente da ideologia de gênero, um ataque à família, à moral, à sexualidade "normal". Toda essa produção de um pânico moral em torno de tal “ideologia" se tornou um instrumento de mobilização social das vertentes políticas de direita, conservadoras, fundamentalistas religiosas. Criar a ideia de que os estudos e discussões sobre gênero seriam uma ameaça à família é uma forma de mobilização social, por meio do medo. É mais fácil mobilizar a população contra grupos sociais ou pensamentos políticos que supostamente querem o mal de seus filhos - aqui materializado no medo de uma "epidemia" da homossexualidade - do que convocar as pessoas para o debate político ou econômico mais amplo.

Ao denunciar que são "políticos os próprios termos pelos quais a identidade é articulada”, Butler (2003, p. 213) ainda ousa propor uma política pós-identitária, pois “o 
fundacionismo é que ele presume, fixa e restringe os próprios sujeitos que espera representar e libertar”. Em outras palavras, para a teórica, a noção de identidade fixa, embora tente libertar opressões, pode ser restrita e acabar por manter os sujeitos presos a armadilhas conservadoras e opressivas. Assim, chama atenção dos próprios movimentos sociais nessa luta, e sugere uma "política não fosse mais compreendida como um conjunto de práticas derivadas dos supostos interesses de sujeitos prontos", pois seria pela fluidez e pela diversidade, longe de identidades perenes, que seria possível surgir uma nova configuração política.

Que desafios sua teoria nos traz? Teriam relação esses debates de gênero e o sistema democrático? Em entrevista recente a um jornal de ampla circulação no Brasil, Butler (2017) dedicou-se a escrever de maneira acessível sua teoria e responder aos ataques vivenciados, quando afirmou: "Quando a violência e ódio se tornam instrumentos da política e da moral religiosa, então a democracia é ameaçada por aqueles que pretende ameaçar todo o tecido social, punir as diferenças e sabotar os vínculos sociais necessários, para sustentar nossa conveniência aqui na terra".

Tornar a vida vivível, justa para todos! Essa é a principal mensagem dessa autora, em seus debates sobre gênero e democracia.

\title{
PERFORMANCES OR GENDER IDEOLOGY? NA APPROACH OF THOUGHT OF JUDITH BUTLER
}

\begin{abstract}
For almost 30 years, the theoretical and political contributions of the American philosopher Judith Butler have been highlighted to discuss some concepts and to cause deconstruction within feminist theory. Considering the author 's relevance for the present, this article intends to make an approach to her work, emphasizing the place of her theory in feminist studies and discussing some fundamental notions. One questions accompanies this analysis: Why is Butler's thinking so threatening? Creating the idea that gender studies are a threat to the family turns out to be a means of social mobilization through fear and hatred for political ends, sometimes conservative and dangerously extremist.
\end{abstract}

Keywords: Gender; queer theory; gender performances.

\section{RESUMEN}

Hace casi 30 años, las contribuciones teóricas y políticas de la filósofa estadounidense Judith Butler han recibido destaque en el escenario mundial, al buscar problematizar algunos conceptos, como el de género, y provocar desconstrucciones dentro de la propia teoría feminista. Considerando la relevancia de la autora para la actualidad, se objetiva en este 
artículo realizar una aproximación a su obra, presentando nociones como sujeto, cuerpo, materialidad, cuerpos abyectos y desempeño de género para problematizar sobre la supuesta "ideología de género", de la cual ella sería una de las proponentes. Una pregunta acompaña al presente análisis: ¿por qué el pensamiento de Butler es tan amenazador? Crear la idea de que los estudios sobre género constituyen una amenaza para la familia acaba convirtiéndose en una forma de movilización social, a través del miedo y el odio con fines políticos, a veces conservadores $y$, peligrosamente, extremistas.

\section{REFERÊNCIAS}

ABBAGNANO, N. Dicionário de filosofia. São Paulo: Martins Fontes, 2003.

BARBIERE, T. Sobre a categoria gênero: uma introdução teórico-metodológica. Recife: SOS Corpo: Gênero e Cidadania, 1993.

BENTO, B. A reinvenção do corpo. Sexualidade na experiência transexual. Rio de Janeiro: Garamond, 2006.

BESSA, K. Posições de sujeito, atuações de gênero. Revista Estudos Feministas. Rio de Janeiro, 6 (1), 34-46. 1998.

BUTLER, J. Corpos que pesam: sobre os limites discursivos do sexo. In: LOURO, G. L. (Org.). O corpo educado. Belo Horizonte: Autêntica, 2001.

BUTLER, J. Criticamente subversiva. In: JIMÉNEZ, R. M. M. (Org.). Sexualiades transgresoras: una antologia de estudios queer. Barcelona: Icaria, 2002.

BUTLER, J. Fundamentos contingentes: o feminismo e a questão do pós-moderno. Cadernos Pagu, 11, 11-28. 1998.

BUTLER, J. Problemas de Gênero: feminismo e subversão da identidade. 2 ed. Rio de Janeiro, 2008.

BUTLER, J. Judith Butler escreve sobre sua teoria de gênero e o ataque sofrido no Brasil.

Folha de São Paulo, São Paulo, 19 nov. 2017. Disponível em:

http://www1.folha.uol.com.br/ilustrissima/2017/11/1936103-judith-butler-escreve-sobre-ofantasma-do-genero-e-o-ataque-sofrido-no-brasil.shtml. Acesso em: 21 nov. 2017.

CHAUÍ, M. O que é ideologia? São Paulo: Brasiliense, 2008.

DELEUZE, G. O mistério de Ariana. (2a. ed.) Lisboa: Passagens, 2005.

FOUCAULT, M. Microfísica do poder. (26a. ed.) Rio de Janeiro: Graal, 2008. 
GELEDÉS. Instituto da Mulher Negra. Disponível em: https://www.geledes.org.br/. Acesso em: 20 out. 2017.

LIMA, L. Estudos de gênero versus ideologia: desafios da teologia. Mandrágora, 21(2), 89112. 2015 .

OEA. Organização dos Estados Americanos. Convenção Interamericana para Prevenir, Punir e Erradicar a Violência Contra a Mulher. 1994. Disponível em: http://www.onumulheres.org.br/wp-content/uploads/2013/03/convencaobelem1994.pdf.

Acesso em: 20 nov. 2017.

ONU. Organização das Nações Unidas. Declaração Universal dos Direitos Humanos. 1948. Disponível em: http://unesdoc.unesco.org/images/0013/001394/139423por.pdf. Acesso em: 20 nov. 2017.

PASSOS, E. Ética e psicologia: teoria e prática. São Paulo: Vetor, 2007.

REIS, T.; EGGERT, E. Ideologia de gênero: uma falácia construída sobre os planos de educação brasileiro. Educ. Soc., Campinas, 38(138), 9-26. 2017.

SCALA, J. Ideologia de gênero: o neototalitarismo e a morte da família. São Paulo: Katechesis, 2011.

SCOTT, J. Gênero: uma categoria útil de análise histórica. Educação \& Realidade. 20 (2), 71-99. 1995.

WAISELFISZ, J. Mapa da violência 2016: homicídios por arma de fogo no Brasil. Brasília: Flacso Brasil, 2016.

\section{Sobre os autores}

Márcio Bruno Barra Valente é mestre em Psicologia pela Universidade Federal de Pernambuco. Coordenador do curso de Psicologia. Professora da Universidade da Amazônia. Coordenador do Grupo de Estudos Psicologia, Narrativa e Crise (GEPNAC). Endereço eletrônico: barra_valente@unama.br

Bárbara Araújo Sordi é mestre e doutoranda em Psicologia pela Universidade Federal do Pará. Professora da Universidade da Amazônia. Coordenadora do Grupo "Relações de gênero, Feminismos e Violências". Endereço eletrônico: barbarasordi@ hotmail.com

Maria Lúcia Chaves Lima é doutora em Psicologia Social pela Pontifícia Universidade Católica de São Paulo. Professora da Pós-Graduação em Psicologia da Universidade Federal do Pará. Endereço eletrônico: marialuciacl@ gmail.com 